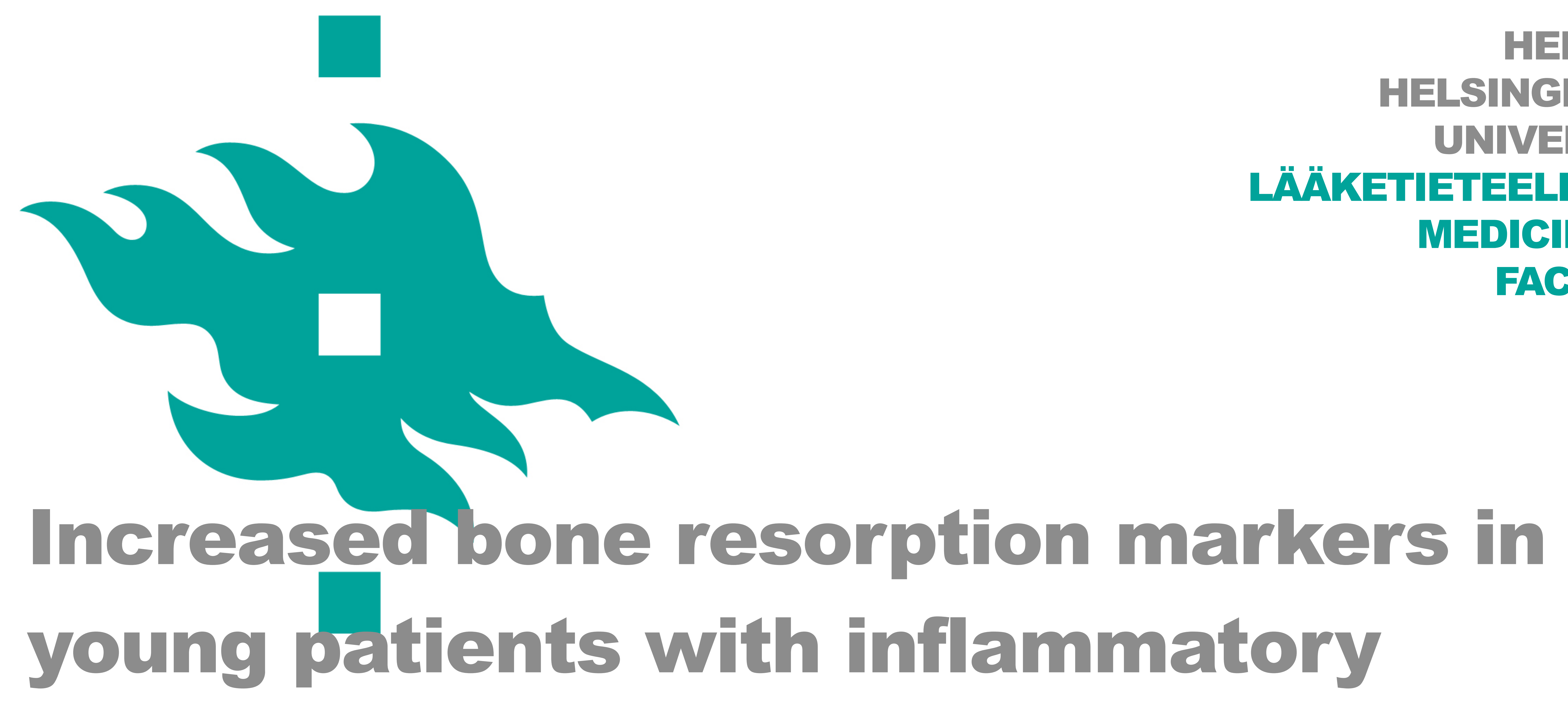

HELSINGIN YLIOPISTO HELSINGFORS UNIVERSITET UNIVERSITY OF HELSINKI

FACULTY OF MEDICINE

\title{
bowel disease
}

${ }^{1}$ Children's Hospital, University of Helsinki and University Hospital of Helsinki, Finland

${ }^{2}$ Folkhälsan Research Center, Biomedicum Helsinki, Finland saila.laakso@helsinki.fi

\section{INTRODUCTION}

Children and adolescents with inflammatory bowel disease (IBD) have defects in bone mineral density (BMD) and bone structure that do not completely normalize with IBD remission.

\section{The objective of the study was to} determine bone turnover marker (BTM) concentrations and factors behind altered bone metabolism in adolescents and young adults with IBD in a casecontrol setting.

\section{METHODS}

This study involved 42 adolescents and young adults (age range from 10.7 to $25.0 \mathrm{yr}$ ) with ulcerative colitis $(n=28)$ or Crohn's disease $(n=14)$ and in 42 age and sex-matched control subjects. We measured their bone formation marker PINP and bone resorption markers CTX and TRACP5b. Study protocol was approved by Research Ethics Committee.

In patients, bone mineral density (BMD) Z-scores were corrected for bone age when they differed $>1$ yr from calendar age.

PINP and CTX were measured from serum samples with automated methods using the IDS-iSYS automated analyzer (IDS Ltd) and TRACP5b using a manual assay (BoneTRAP(R); IDS Ltd).

Student's $t$ test and univariate linear model with age and BMI as covariates were used for normally distributed parameters. Mann Whitney U-test was used for non-parametric testing.

\section{RESULTS}

Half of the patients had disease duration over $8.5 \mathrm{yrs}$ and $62 \%$ of patients were in clinical remission. Patients with IBD were shorter and had lower BMI than controls. Whole body bone area and bone mineral content were lower in them. BMD Z-scores were decreased for lumbar spine and whole body in comparison to controls (Table 1).

TABLE 1. Characteristics of the $\mathbf{4 2}$ patients with inflammatory bowel disease and their controls.

\begin{tabular}{|c|c|c|c|}
\hline $\begin{array}{l}\text { Characteristic } \\
\text { Mean } \\
(95 \% \mathrm{Cl})\end{array}$ & IBD patients & Control subjects & P value \\
\hline Age $(y r)$ & $\begin{array}{c}18.8 \\
(17.6-20.1)\end{array}$ & $\begin{array}{c}19.2 \\
(18.4-19.9)\end{array}$ & 0.7 \\
\hline $\begin{array}{l}\text { Gender } \\
\text { (male / female) }\end{array}$ & $20 / 22$ & $20 / 22$ & \\
\hline Height $(\mathrm{cm})$ & $\begin{array}{c}167 \\
(163-170)\end{array}$ & $\begin{array}{c}173 \\
(170-177)\end{array}$ & 0.012 \\
\hline BMI $\left(\mathrm{kg} / \mathrm{m}^{2}\right)$ & $\begin{array}{c}20.8 \\
(19.8-21.7)\end{array}$ & $\begin{array}{c}22.4 \\
(21.4-23.4)\end{array}$ & 0.025 \\
\hline $\begin{array}{l}\text { Whole body BA } \\
\left(\mathrm{cm}^{2}\right)\end{array}$ & $\begin{array}{c}2125 \\
(2029-2220)\end{array}$ & $\begin{array}{c}2336 \\
(2244-2428)\end{array}$ & 0.002 \\
\hline $\begin{array}{l}\text { Whole body BMC } \\
\text { (g) }\end{array}$ & $\begin{array}{c}2024 \\
(1875-2173)\end{array}$ & $\begin{array}{c}2719 \\
(2251-2887)\end{array}$ & $<0.001$ \\
\hline $\begin{array}{l}\text { Lumbar spine } \\
\text { BMD Z-score }\end{array}$ & $\begin{array}{c}-0.7 \\
(-1.0--0.4)\end{array}$ & $\begin{array}{c}-0.2 \\
(-0.5-0.1)\end{array}$ & 0.040 \\
\hline $\begin{array}{l}\text { Whole body BMD } \\
\text { Z-score }\end{array}$ & $\begin{array}{c}-0.5 \\
(-0.8--0.2)\end{array}$ & $\begin{array}{c}0.1 \\
(-0.3-0.4)\end{array}$ & 0.011 \\
\hline
\end{tabular}

IBD, inflammatory bowel disease; BA, bone area; BMC, bone mineral content; BMD, bone mineral density. $P$ values are from Student's $t$ test.

TRACP5b was higher in patients with IBD [geometric mean, (95\% CI), $5.6 \mathrm{U} / \mathrm{L}(4.6-6.7)$ vs. $4.4(3.9-5.0), p=0.001$, Figure 1], when adjusting for age and whole-body bone area, but no significant difference in PINP [median (IQR) $106 \mathrm{ng} / \mathrm{mL}(53-403)$ vs. $92(60-159)$, $\mathrm{p}=0.6$ ] or CTX [geometric mean $(95 \% \mathrm{CI}) 1.02$ $\mathrm{ng} / \mathrm{mL}(0.82-1.27)$ vs. $0.97(0.83-1.14)$, $\mathrm{p}=0.4]$ was observed.

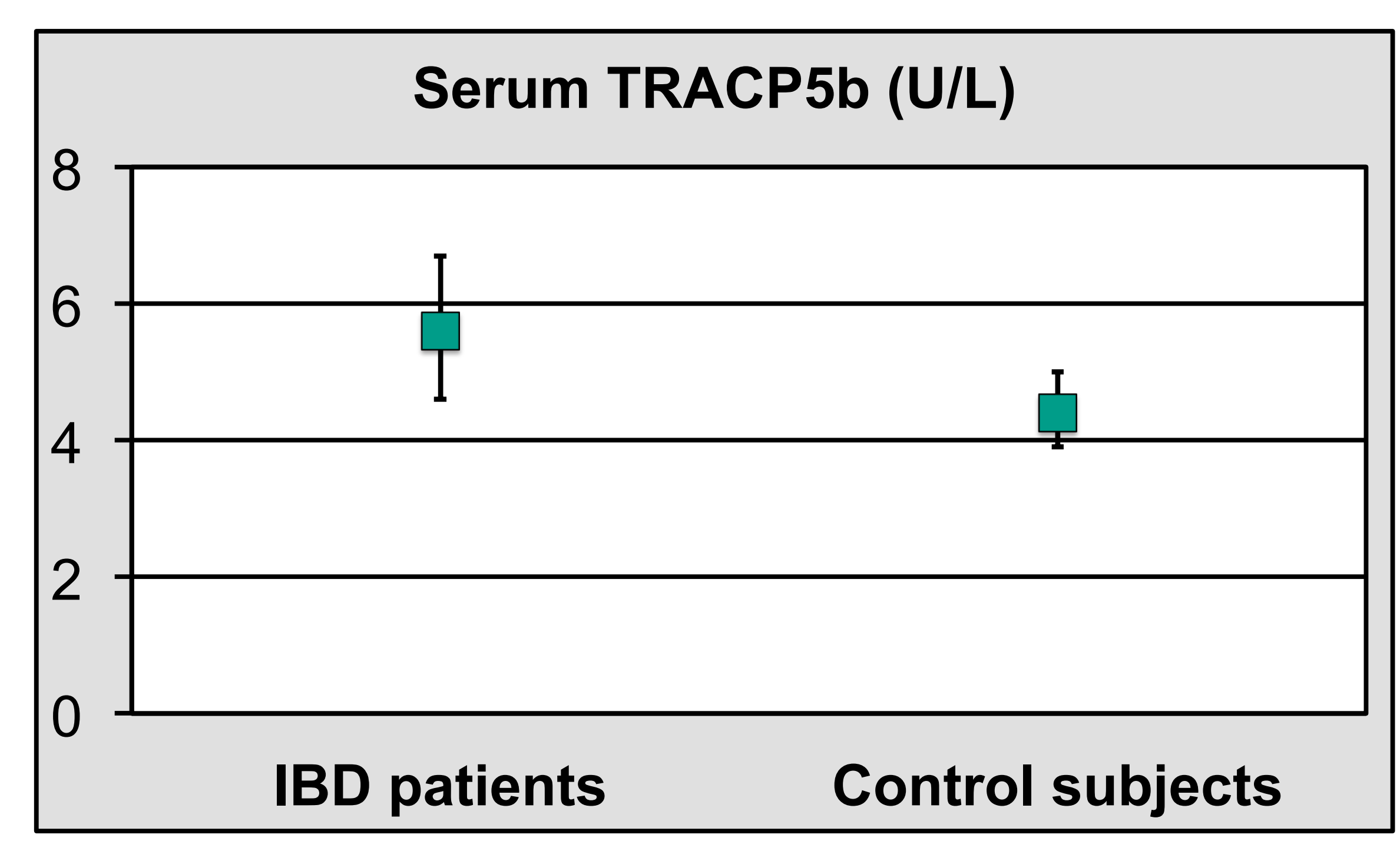

FIGURE 1. Serum TRACP5b concentration in 42 IBD patients and 42 age- and gender-matched control subjects [geometric mean $(95 \% \mathrm{Cl}$ for mean), $\mathrm{p}=0.001$ ]

In the patient group, all BTMs were significantly lower in postpubertal subjects when compared to prepubertal and pubertal subjects as expected $(\mathrm{p}<0.05)$.

Current use of contraceptive pills associated with lower PINP [n=6 vs. $\mathrm{n}=12 ; 39 \mathrm{ng} / \mathrm{mL}$ $(33-47)$ vs. 94 (73-121, $\mathrm{p}<0.001]$ and CTX [0.47 ng/mL (0.32-0.69) vs. 0.80 (0.61-1.06), $\mathrm{p}=0.014]$ concentrations in patients with IBD.

Clinical remission of IBD did not associate with any statistically significant difference in BTM concentrations.

\section{CONCLUSIONS}

Based on the BTM concentrations, bone health is compromised in young patients with IBD, though in clinical remission. BTMs reflect increased bone resorption, which could contribute to lower BMD.

The authors have no conflicts of interest to report. 